\title{
Optimization of the Culture Conditions of Kombucha Cellulose by Response Surface Methodology
}

\author{
Liu Yan, Dai Xujie \\ College of Biological Foods, Changchun University of Science and Technology, Changchun, China
}

Email address:

410853394@qq.com (Liu Yan), 284679766@qq.com (Dai Xujie)

\section{To cite this article:}

Liu Yan, Dai Xujie. Optimization of the Culture Conditions of Kombucha Cellulose by Response Surface Methodology. Science Discovery. Vol. 5, No. 5, 2017, pp. 307-311. doi: 10.11648/j.sd.20170505.11

Received: June 21, 2017; Accepted: July 10, 2017; Published: July 19, 2017

\begin{abstract}
Kombucha cellulose is a kind of secondary metabolites produced by microorganisms. It is a kind of extracellular polysaccharide which is linked with $\beta-1,4$ glycosides. Compared with lignocellulose, it is the key focus of the current research in society, with a complex three dimensional reticular structure,material-combining ability, good biocompatibility, high purity, outstanding water-holding capacity, whichcan play an important role in many areas. Optimization of culture medium by response surface method to determine the optimum Kombucha culture conditions. The optimum culture condition was: Black Tea 2.16g, sucrose $27.33 \mathrm{~g}$, bran $4.35 \mathrm{~g}$, inoculum $23.03 \%$,culture $48 \mathrm{~h}$, under these conditions, the growth of biofilm thickness of Kombucha can reach $0.76 \mathrm{~cm}$. At the same time, the growth rate and the establishment of Kombucha Black Tea between sucrose, wheat bran and the inoculation amount of two polynomial model, the model can predict the growth status of Kombucha, can obtain the optimal conditions.
\end{abstract}

Keywords: Kombucha Cellulose, Optimization, Culture Conditions, Response Surface

\section{响应面分析法优化红茶菌纤维素的培养条件}

刘艳, 戴旭杰

生物食品学院, 长春科技学院, 长春, 中国

邮箱

410853394@qq.com(刘艳),284679766@qq.com（戴旭杰）

摘要: 红茶菌纤维素是一种由微生物共生生长的纳米纤维素膜, 它跟木质纤维素相比, 具有复杂的网状三维立体结构、 与材料结合能力强, 生物相容性良好、纯度非常高、持水能力出色, 是当前社会研究的重点方向, 在许多领域都能发 挥出重要的作用。利用响应面法对红茶菌的培养基进行优化, 确定其最佳培养条件。最佳的培养条件为: 红茶 $2.16 \mathrm{~g}$ 、 蔗糖 $27.33 \mathrm{~g}$ 、麦麸 $4.35 \mathrm{~g}$ 、接种量 $23.03 \%$, 培养时间 $48 \mathrm{~h}$, 在此培养条件下, 红茶菌膜的生长厚度可达到 $0.76 \mathrm{~cm}$ 。同时 建立红茶菌种生长速率与红茶、蔗糖、麦鈇和接种量之间的二次多项式模型, 该模型可以很好地预测红茶菌的生长状 况，可以获得最优的工艺条件。从而获得生长速度最快的红茶菌纤维素膜的制备。

关键词: 红茶菌纤维素膜, 优化, 培养条件, 响应面 


\section{1. 前言}

纤维素具体分为两种, 一种为木质纤维素, 另一种为 微生物纤维素 [1]。红茶菌纤维素是一种由 $\beta-1,4$ 糖苷键交 互形成的葡糖聚合物, 直径约为 $50 \mathrm{~nm}$, 由红茶菌产生, 它是一种胞外多糖[2], 红茶菌纤维跟木质纤维素相比, 最 大的区别是其纯度极其之高, 而木质纤维素的成分一般为 半纤维素, 它们的含水量很高[3]。Yamanaka等[4]人的实 验结果表明红茶菌纤维素结晶度非常高, 其机械耐压性能 远高于木质纤维素。因为它出色的机械耦合方面能力使其 在纳米原料范畴内具有普遍的运用。在制作医用绷带、人 造血管、组织软骨和组织修复、人造皮肤、人工血管、神 经外科、骨组织工程以及膝盖半月板等医学领域方面具有 深远的应用。其天然的特性和良好的吸水性导致它成为制 作软组织透水性隐形眼镜的绝佳材料 [5], 同时它使纳米生 物材料之间的相融变得简单, 因此它是制作心血管纳米材 料的理想原料。它在其他应用领域方面也有广泛应用, 例 如声膜片, 在燃料电池中作为电极组件, 也能成为光反式 复合材料和电子显示器[6]。西方国家有用细菌纤维素制作 的滤膜器, 应用于一些细胞培养、高强度纸杯、可再利用 的贞儿尿布、高仿真的人造皮革、增稠剂、增强剂、护手 霜方面的化妆品。日本利用细菌纤维素摸制备音箱、麦克 以及耳麦的声震膜[7]。这些令人兴奋的运用取决于细菌纤 维素工业上的大范围生产。

因此利用红茶菌发酵法制造产生纤维素膜具有可观 的收益, 并且, 市场需求极高。而且当前社会红茶菌纤维 素的产量普遍都处于较低的水平, 因此对于微生物发酵生 产纤维素对满足今后社会的需求具有重要意义。

\section{2. 材料与方法}

\section{1. 材料与设备}

红茶菌(发酵实验室), 蔗糖, 麦敖, 红茶均为市售。
分析天平, AUY220, SHIMADZU PHILIPPINES; 生 化培养箱, SHP-250, 上海精宏实验设备有限公司; 高压 蒸汽灭菌器, CL-32L, 日本ALP公司。

\section{2. 培养方法}

制备茶糖液 $\rightarrow$ 接种 $\rightarrow$ 混合发酵 $\rightarrow$ 获取菌膜。

\section{3. 单因素实验设计}

\section{3. 1. 红茶加入量对菌膜生长速率的影响}

分别采用红茶加入量为 $1 \mathrm{~g} 、 2 \mathrm{~g} 、 3 \mathrm{~g} 、 4 \mathrm{~g} 、 5 \mathrm{~g} 、 6 \mathrm{~g}$ 六个 水平, 在蔗糖 $25 \mathrm{~g}$, 麦麸 $4 \mathrm{~g}$ 和接菌量 $20 \%$ 的条件下培养 $48 \mathrm{~h}$, 以红茶菌膜的厚度值确定最佳红茶加入量。

\subsection{2. 蔗糖加入量对菌膜生长速率的影响}

分别采用蔗糖加入量为 $10 \mathrm{~g} 、 15 \mathrm{~g} 、 20 \mathrm{~g} 、 25 \mathrm{~g} 、 30 \mathrm{~g}$ 、 $35 \mathrm{~g}$ 六个水平，在红茶 $2 \mathrm{~g}$, 麦麸 $4 \mathrm{~g}$ 和接菌量 $20 \%$ 的条件下 培养 $48 \mathrm{~h}$, 以红茶菌膜的厚度值确定最佳庶糖加入量。

\section{3. 3. 麦敖加入量对菌膜生长速率的影响}

分别采用麦敖加入量为 $1 \mathrm{~g} 、 2 \mathrm{~g} 、 3 \mathrm{~g} 、 4 \mathrm{~g} 、 5 \mathrm{~g} 、 6 \mathrm{~g}$ 六个 水平, 在红茶 $2 \mathrm{~g}$, 蔗糖 $25 \mathrm{~g}$ 和接菌量 $20 \%$ 的条件下培养 $48 \mathrm{~h}$, 以红茶菌膜的厚度值确定最佳麦敖加入量。

\subsection{4. 接种量对菌膜生长速率的影响}

分别采用接种量为 $0 \% 、 10 \% 、 20 \% 、 30 \% 、 40 \%$ 、 $50 \%$ 六个水平, 在红茶 $2 \mathrm{~g}$, 蔗糖 $25 \mathrm{~g}$ 和麦麸 $4 \mathrm{~g}$ 的条件下培 养 $48 \mathrm{~h}$, 以红茶菌膜的厚度值确定最佳接种量。

\section{4. 响应面优化设计}

参考 Box-Behnken 实验设计 [8], 以影响红茶菌膜的生 长情况的四个因素: 红茶加入量 $\mathrm{X}_{1}$ 、蔗糖加入量 $\mathrm{X}_{2}$ 、麦 敖加入量 $X_{3}$ 和接菌量 $X_{4}$ 为考察因子, 编码值 $1 、 0 、-1$ 分别表示自变量中的高中低水平, 实验设计如表 1 所示。

表1 Box-Behnken实验设计因子及编码值。

\begin{tabular}{lllll}
\hline \multirow{2}{*}{ 水平 } & 因素 & & & \\
\cline { 2 - 5 } & $\mathbf{X}_{1}$ 红茶量 $(\mathbf{g})$ & $\mathbf{X}_{2}$ 蔗糖量 $(\mathbf{g})$ & $\mathbf{X}_{3}$ 麦麸 $(\mathbf{g})$ & $\mathbf{X}_{4}$ 接菌量 $(\mathbf{\%})$ \\
\hline-1 & 1 & 25 & 4 & 20 \\
0 & 2 & 25 & 5 & 30 \\
+1 & 3 & 30 & 5 & 30 \\
\hline
\end{tabular}

注： -1 代表低水平; 0 代表中间水平; +1 代表高水平。

\section{3. 结果与分析}

\section{1. 单因素实验结果}

\section{1. 1. 红茶加入量对菌膜生长速率的影响}

由图1可以看出, 当红茶加入量为 $1 \mathrm{~g}-2 \mathrm{~g}$ 时, 菌膜的生 长速度不断加快, 并达到最大厚度 $0.52 \mathrm{~cm}$, 继续增加红茶 加入量, 菌膜的生长速度逐渐趋于平缓。因此, 可以确定 红茶的最佳加入量为 $2 \mathrm{~g}$ 。

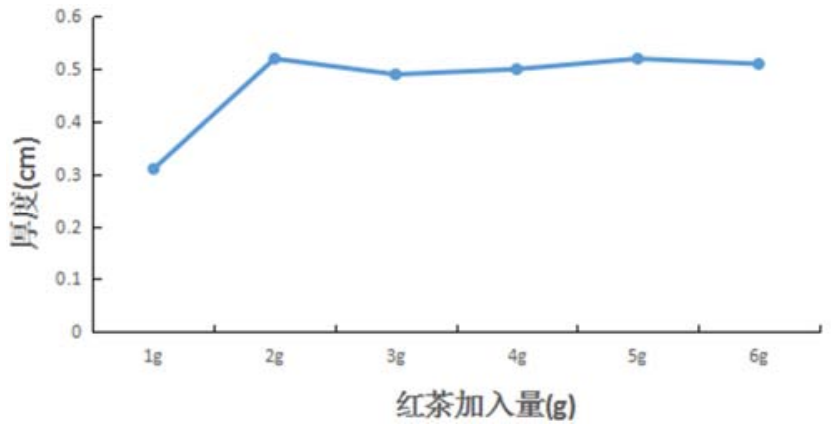

图1 红茶加入量对菌膜生长速率的影响。 


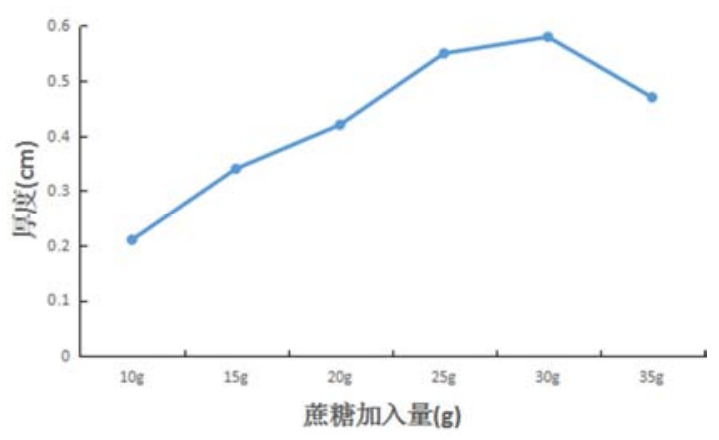

图2 蔗糖加入量对菌膜生长速率的影响。

\subsection{2. 蔗糖加入量对菌膜生长速率的影响}

由图2可以看出, 当蔗糖加入量为 $10 \mathrm{~g}-30 \mathrm{~g}$ 时, 菌膜的 生长速度不断加快, 并达到最大厚度 $0.58 \mathrm{~cm}$, 继续增加蔗 糖加入量, 菌膜的生长速度反而下降。因此, 可以确定蔗 糖的最佳加入量为 $30 \mathrm{~g}$ 。

\section{1. 3. 麦鏯加入量对菌膜生长速率的影响}

由图3可以看出, 麦麸的加入量对菌膜的生长速度影 响并不大, 但在麦敖为 $4 \mathrm{~g}$ 时, 菌膜的生长速度最快, 厚度 达到 $0.51 \mathrm{~cm}$ 。因此, 麦麸的最佳加入量为 $4 \mathrm{~g}$ 。

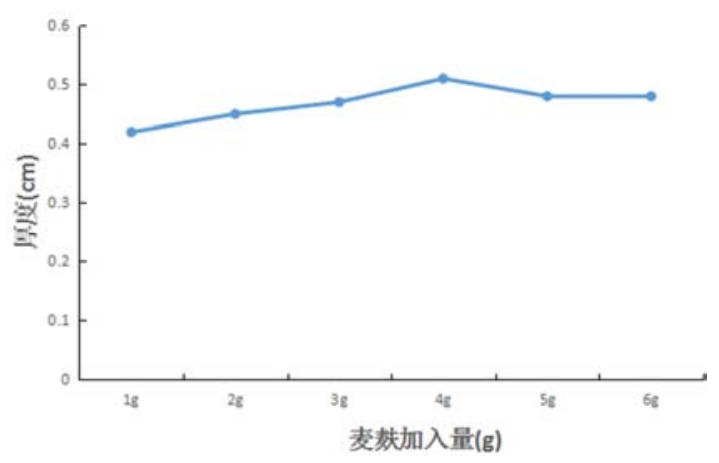

图3 麦敖加入量对菌膜生长速率的影响。

\section{1. 4. 接种量对菌膜生长速率的影响}

由图4可以看出，当接种量为 $0 \%-20 \%$ 的时，菌膜的生 长速度逐渐加快, 并达到最大厚度 $0.53 \mathrm{~cm}$, 继续增加接种 量, 菌膜的生长速度反而逐渐降低。因此, 可以确定接种 量的最佳添加量为 $20 \%$ 。

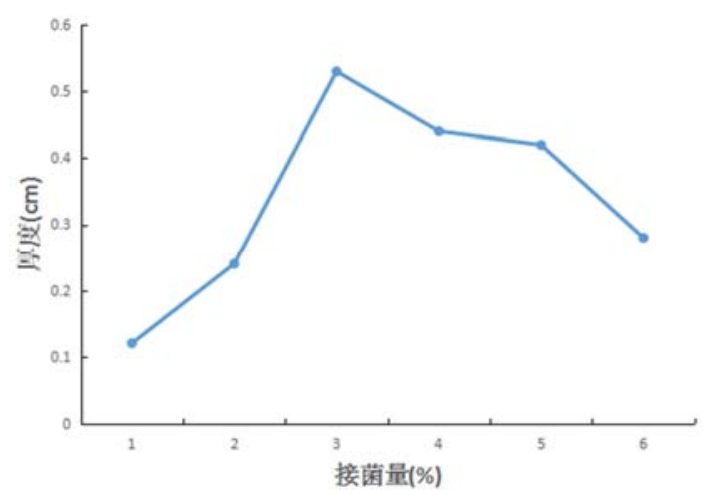

图4 接菌量对菌膜生长速率的影响。

\section{2. 响应面设计结果与分析}

根据单因素结果, 运用Design Expert 8.0.5 软件分别对 红茶加入量、蔗糖加入量、麦堘加入量和接种量进行优化, 实验设计及结果如表2。

表2 响应面实验设计及结果。

\begin{tabular}{|c|c|c|c|c|c|}
\hline 实验号 & $X_{1}$ 红茶 & $\mathbf{X}_{2}$ 蔗糖 & $\mathbf{X}_{3}$ 麦敖 & $\mathrm{X}_{4}$ 接菌量 & $\mathbf{Y}_{1}$ 生长厚度 \\
\hline 1 & 2.0 & 25.0 & 4.0 & 20 & 0.74 \\
\hline 2 & 2.0 & 25.0 & 4.0 & 20 & 0.72 \\
\hline 3 & 2.0 & 25.0 & 5.0 & 10 & 0.46 \\
\hline 4 & 2.0 & 20.0 & 4.0 & 10 & 0.42 \\
\hline 5 & 2.0 & 30.0 & 3.0 & 20 & 0.58 \\
\hline 6 & 2.0 & 20.0 & 4.0 & 30 & 0.38 \\
\hline 7 & 1.0 & 25.0 & 4.0 & 10 & 0.41 \\
\hline 8 & 1.0 & 25.0 & 4.0 & 30 & 0.54 \\
\hline 9 & 2.0 & 30.0 & 5.0 & 20 & 0.7 \\
\hline 10 & 3.0 & 25.0 & 3.0 & 20 & 0.59 \\
\hline 11 & 2.0 & 25.0 & 4.0 & 20 & 0.73 \\
\hline 12 & 2.0 & 20.0 & 3.0 & 20 & 0.57 \\
\hline 13 & 1.0 & 20.0 & 4.0 & 20 & 0.42 \\
\hline 14 & 2.0 & 25.0 & 4.0 & 20 & 0.74 \\
\hline 15 & 2.0 & 20.0 & 5.0 & 20 & 0.41 \\
\hline 16 & 3.0 & 30.0 & 4.0 & 20 & 0.63 \\
\hline 17 & 2.0 & 30.0 & 4.0 & 30 & 0.61 \\
\hline 18 & 3.0 & 25.0 & 4.0 & 30 & 0.6 \\
\hline 19 & 3.0 & 20.0 & 4.0 & 20 & 0.43 \\
\hline 20 & 2.0 & 30.0 & 4.0 & 10 & 0.48 \\
\hline 21 & 2.0 & 25.0 & 4.0 & 20 & 0.73 \\
\hline 22 & 2.0 & 25.0 & 5.0 & 30 & 0.66 \\
\hline 23 & 2.0 & 25.0 & 3.0 & 10 & 0.43 \\
\hline 24 & 2.0 & 25.0 & 3.0 & 30 & 0.61 \\
\hline 25 & 1.0 & 25.0 & 5.0 & 20 & 0.57 \\
\hline 26 & 3.0 & 25.0 & 5.0 & 20 & 0.58 \\
\hline 27 & 3.0 & 25.0 & 4.0 & 10 & 0.48 \\
\hline 28 & 1.0 & 25.0 & 3.0 & 20 & 0.59 \\
\hline 29 & 1.0 & 30.0 & 4.0 & 20 & 0.53 \\
\hline
\end{tabular}

\subsection{1. 回归方程建立}

通过以红茶菌膜的生长厚度作为响应值运用响应面 软件对表 3-5 的实验结果进行数据分析, 二次回归方程拟 合后, 可以获得的 4 个因素与红茶菌膜生长厚度之间的多 元二次回归模拟方程为:

$$
\begin{gathered}
\mathrm{Y}_{1}=0.73+0.021 \mathrm{X}_{1}+0.075 \mathrm{X}_{2}+0.0008333 \mathrm{X}_{3}+0.060 \mathrm{X}_{4}+ \\
0.022 \mathrm{X}_{1} \mathrm{X}_{2}+0.0025 \mathrm{X}_{1} \mathrm{X}_{3}-0.0025 \mathrm{X}_{1} \mathrm{X}_{4}+0.07 \mathrm{X}_{2} \mathrm{X}_{3}+ \\
0.042 \mathrm{X}_{2} \mathrm{X}_{4}+0.005 \mathrm{X}_{3} \mathrm{X}_{4}-0.098 \mathrm{X}_{1}^{2}-0.12 \mathrm{X}_{2}^{2}-0.051 \mathrm{X}_{3}^{2}-0.13 \mathrm{X}_{4}^{2}
\end{gathered}
$$

上式中的 $X_{1} \sim X_{4}$ 分别为表 3-5 中的四个自变量的编码 值, $\mathrm{Y}_{1}$ 为表 6 中的响应值。

\subsection{2. 方差分析}

对回归方程进行显著性检查、方差分析, 结果如表3 所示。 
表3 响应面实验方差分析。

\begin{tabular}{|c|c|c|c|c|c|c|}
\hline 方差来源 & 平方和 & 自由度 & 均方 & F值 & P值 & 显著性 \\
\hline $\mathrm{X}_{1}$ & 0.005208 & 1 & 0.005208 & 4.54 & 0.0514 & * \\
\hline $\mathrm{X}_{2}$ & 0.067 & 1 & 0.067 & 58.8 & $<0.0001$ & $* *$ \\
\hline $\mathrm{X}_{3}$ & 0.00000833 & 1 & 0.0000083 & 0.00726 & 0.9333 & \\
\hline $\mathrm{X}_{4}$ & 0.043 & 1 & 0.043 & 37.63 & $<0.0001$ & ** \\
\hline $\mathrm{X}_{1} \mathrm{X}_{2}$ & 0.002025 & 1 & 0.002025 & 1.76 & 0.2054 & \\
\hline $\mathrm{X}_{1} \mathrm{X}_{3}$ & 0.0000250 & 1 & 0.0000250 & 0.022 & 0.8848 & \\
\hline $\mathrm{X}_{1} \mathrm{X}_{4}$ & 0.0000250 & 1 & 0.0000250 & 0.022 & 0.8848 & \\
\hline $\mathrm{X}_{2} \mathrm{X}_{3}$ & 0.020 & 1 & 0.02 & 17.07 & 0.001 & $* *$ \\
\hline $\mathrm{X}_{2} \mathrm{X}_{4}$ & 0.00723 & 1 & 0.00723 & 6.29 & 0.025 & \\
\hline $\mathrm{X}_{3} \mathrm{X}_{4}$ & 0.00010 & 1 & 0.00010 & 0.087 & 0.7722 & \\
\hline $\mathrm{X}_{1}^{2}$ & 0.062 & 1 & 0.062 & 54.36 & $<0.0001$ & $* *$ \\
\hline $\mathrm{X}_{2}^{2}$ & 0.1 & 1 & 0.1 & 87.35 & $<0.0001$ & $* *$ \\
\hline $\mathrm{X}_{3}{ }^{2}$ & 0.017 & 1 & 0.017 & 14.46 & 0.0019 & $* *$ \\
\hline $\mathrm{X}_{4}^{2}$ & 0.12 & 1 & 0.12 & 101.96 & $<0.0001$ & \\
\hline 模型 & 0.35 & 14 & 0.025 & 21.79 & $<0.0001$ & $* *$ \\
\hline 残差 & 0.016 & 14 & 0.00115 & & & \\
\hline 失拟项 & 0.016 & 10 & 0.00158 & 22.56 & 0.43 & \\
\hline 纯误差 & 0.00028 & 4 & 0.00007 & & & \\
\hline 总和 & 0.37 & 28 & & & & \\
\hline
\end{tabular}

注: *表示显著 $(\mathrm{P}<0.05), * *$ 表示极显著 $(\mathrm{P}<0.01)$ 。

该多元二次回归方程模型 $\mathrm{F}$ 值检验数据为极显著 $(\mathrm{P}<0.01)$, 而该方程的失拟项不显著, 模型分析显著, 表明方程模拟的比较好, 故此次模拟的多元二次回归方程 与现实情况较为吻合, 误差小, 能明确的反映出上诉各个 因素与响应值之间的联系, 也表明因素水平之间的影响并 不是呈现线性关系。在表3响应面实验方差分析中能够发 现, 各个因素之间也存在的相互影响, 其中 $X_{2} 、 X_{4} 、 X_{2} X_{3}$ 、 $\mathrm{X}_{1}{ }^{2} 、 \mathrm{X}_{2}{ }^{2} 、 \mathrm{X}_{3}{ }^{2} 、 \mathrm{X}_{4}{ }^{2}$ 对于响应值都呈现出极显著, $\mathrm{X}_{1}$ 对于 响应值呈现出显著, 而 $X_{3} 、 X_{1} X_{2} 、 X_{1} X_{3} 、 X_{1} X_{4} 、 X_{2} X_{4} 、$ $\mathrm{X}_{3} \mathrm{X}_{4}$ 对于响应值表现出不显著。
从下列各因素之间相互作用的响应面图 (图5到图7) 中 观察可知, 其中若曲线越陡峭, 则表明其作用效果越显著; 而曲线越平稳, 则表明其作用效果越差。从而得知, 蔗糖量、 接种量和红茶之间的曲线较为陡峭, 说明这三者之间对于菌 膜生长厚度起的作用最为显著。并且响应曲面图和其投影的 等高线图, 等高线图形状近乎圆形, 因此表明各个影响因素 与响应值不是简单的线性关系。通过Design-Expert 8.0.5软件 进行分析得：影响菌膜生长厚度的最佳培养条件为：红茶 $2.16 \mathrm{~g}$ 、蔗糖 $27.33 \mathrm{~g}$ 、麦敖 $4.35 \mathrm{~g}$ 、接种量 $23.03 \%$, 在此等条 件下，红茶菌膜的生长厚度可达到 $0.76 \mathrm{~cm}$ 。

\section{红茶与蔗糖对菌膜生长的影响}

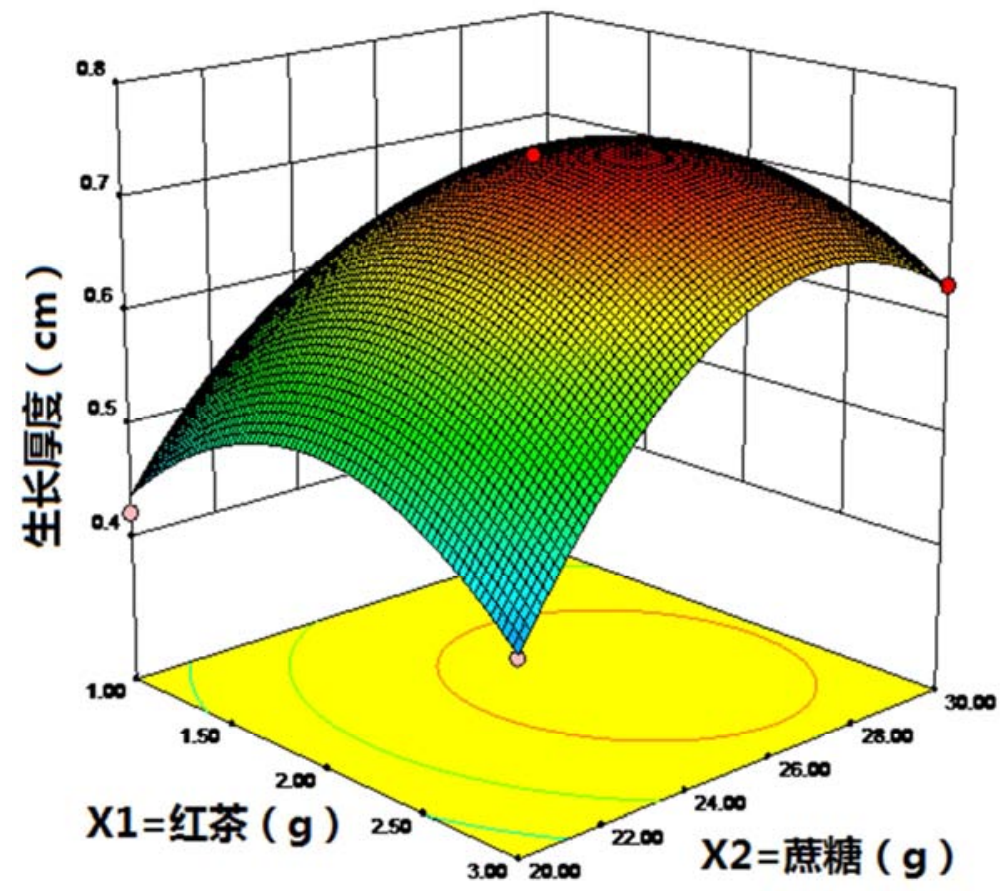

图5 红茶与蔗糖对菌膜生长的影响。 


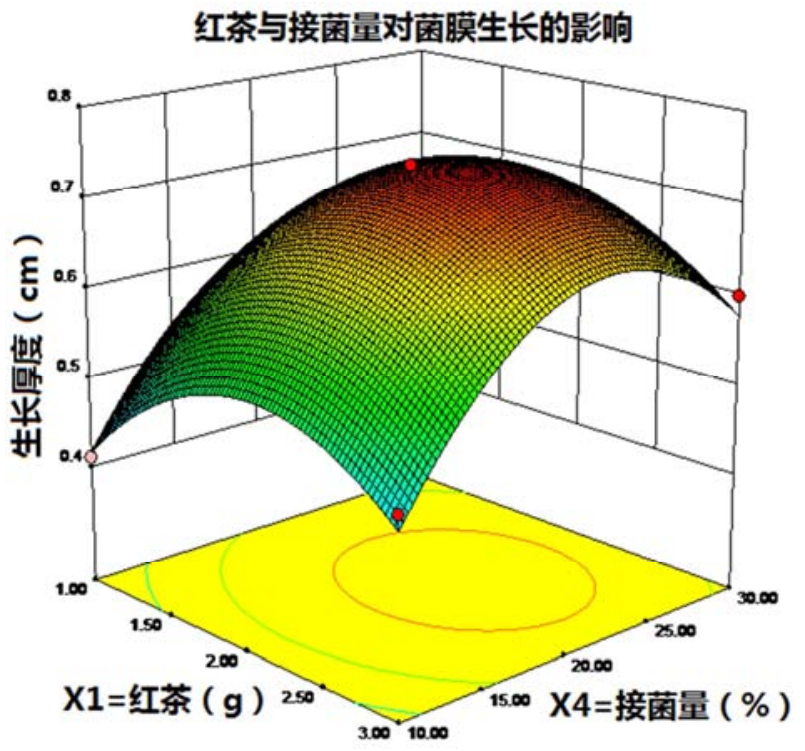

图6 红茶与接菌量对菌膜生长的影响。

\section{接菌量与蔗糖对菌膜生长的影响}

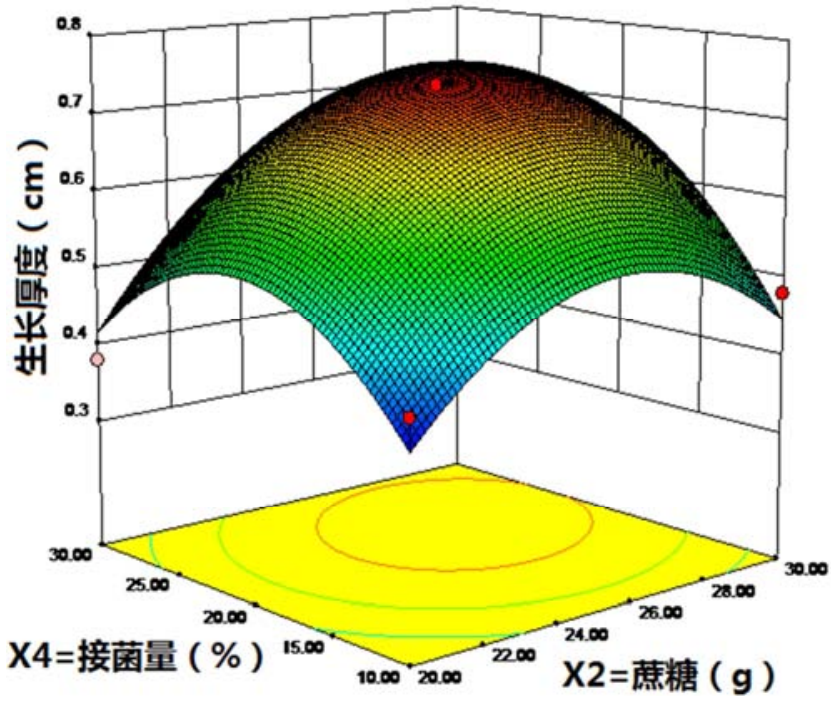

图7 接菌量与蔗糖对菌膜生长的影响。

\section{4. 结论}

利用实验设计软件Design-Expert8.0.5, 通过二次回归 得到了红茶菌膜生长速率与红茶 $2.16 \mathrm{~g}$ 、蔗糖 $27.33 \mathrm{~g}$ 、麦麸 $4.35 \mathrm{~g}$ 、接种量 $23.03 \%$ 的回归模型。经检验证明该模型是 合理可信的, 能够较好地预测红茶菌膜的生长速率。在对 影响红茶菌膜生长速率的关键因素及其相互作用进行探 讨后, 得到的优化工艺参数为: 红茶 $2.16 \mathrm{~g}$ 、蔗糖 $27.33 \mathrm{~g}$ 、 麦敖 $4.35 \mathrm{~g}$ 、接种量 $23.03 \%$ 时, 红茶菌厚度的理论值为 $0.7 \mathrm{~cm}$, 验证实验为 $0.74 \mathrm{~cm}$ 。因此, 利用响应面分析方法 对红茶菌的发酵工艺进行优化, 可以获得最优的工艺参数, 从而为进一步的实验研究奠定基础。

\section{5. 讨论}

细菌纤维素是当前国内外的研究热点, 是最新型生 物材料中重要的一个成员。在食品、医药、物理材料等 领域具有广泛的应用。但是由于产细菌纤维素的主要菌 株生长周期长, 导致其目前并未有大规模的工业生产 [9], 发酵工业并不成熟。本实验主要从实验室角度模拟工业 化生产细菌纤维素的发酵条件。在以后实验室对细菌纤 维素的后续工作可以在以下几个方面重点进行研究: 为 了尽快实现工业化大生产, 在今后的实验研究中, 可以 对篮选出来的菌株进行诱变处理, 以期望能够找出一株 产量高的菌株。

红茶菌纤维素具备强的生物材料相容性, 之后实验可 以相对的将红茶菌纤维素膜与一些复合材料相结合 [10], 以便于研究它在复合材料领域所能发挥的作用同时探索 更多的性质。

\section{参考文献}

[1] 阎章才. 溶纤维素粘细菌的分离纯化, 分类, 及降解纤维 素机理的研究 $[D]$. 济南: 山东大学博士。

[2] 朱清梅, 林强, 冯玉红, 等. 细菌纤维素基材料的制备及 其应用前景 $[\mathrm{J}]$. 海南大学学报: 自然科学版, 2010, 28(2):163-167.

[3] 陈竞, 冯蕾, 杨新平. 细菌纤维素的制备和应用研究进展 [J]. 纤维素科学与技术, 2014, 22(2):58-63。

[4] Iguchi M, Yamanaka S, Budhiono A. Bacterial cellulose-a masterpiece of nature's arts [J]. Journal ofMaterials Science, 2000, 35(2): 261-270.

[5] 武志芳, 张霞, 易涁, 等. 新型生物材料细菌纤维素的研 究进展 $[J]$. 食品与发酵科技, 2010（1）:27-30。

[6] Padrão J, Gonçalves S, Silva J P, et al. Bacterial cellulose-lactoferrin as an antimicrobial ediblepackaging [J]. Food Hydrocolloids, 2016, 58: 126-140.

[7] 许如清. 细菌纤维素基振膜材料的声学性能研究[D]. 东华 大学, 2012。

[8] 刘艳, 冯印等. 响应面法优化产虾青素假单胞菌的发酵培 养基[D]．食品工业科技，2014（20）186-190。

[9] Kornmann H, Duboc P, Niederberger P, et al. Influence of residual ethanol concentration on the growthof Gluconacetobacter xylinus I 2281 [J]. Applied Microbiology \& Biotechnology, 2003, 62(2-3):168-173.

[10] 陈艳梅, 奚廷斐, 郑琪, 等. 细菌纤维素的体内降解及其 组织相容性 [J]. 科技导报, 2009, 27(0921):61-66。 